\title{
The Role of Lower Extremity Amputation in Chronic Limb-Threatening Ischemia
}

\author{
Tanner I. Kim, MD ${ }^{1}$ Carlos Mena, MD $^{2}$ Bauer E. Sumpio, MD, $\mathrm{PhD}^{1,2}$ \\ ${ }^{1}$ Division of Vascular Surgery, Department of Surgery, Yale University \\ School of Medicine, New Haven, Connecticut \\ ${ }^{2}$ Cardiology Section, Department of Medicine, Yale University School \\ of Medicine, New Haven, Connecticut \\ Address for correspondence Bauer E. Sumpio, MD, PhD, Department \\ of Surgery, Radiology, and Medicine, Yale University School of \\ Medicine, 330 Cedar Street, BB204C, New Haven, CT 06520 \\ (e-mail: bauer.sumpio@yale.edu).
}

Int J Angiol 2020;29:149-155.

\author{
Abstract \\ Keywords \\ - amputation \\ - peripheral artery \\ disease \\ - chronic limb- \\ threatening ischemia \\ - artery \\ - risk factors \\ - end-stage renal \\ disease
}

Chronic limb-threatening ischemia (CLTI) is a severe form of peripheral artery disease associated with high rates of limb loss. The primary goal of treatment in CLTI is limb salvage via revascularization. Multidisciplinary teams provide improved care for those with CLTI and lead to improved limb salvage rates. Not all patients are candidates for revascularization, and a subset will require major amputation. This article highlights the role of amputations in the management of CLTI, and describes the patients who should be offered primary amputation.
Chronic limb-threatening ischemia (CLTI) represents the end rates of limb loss and mortality. ${ }^{1,2}$ Surgical and endovascular revascularization are the primary treatment modalities to improve perfusion and avoid amputation. Multidisciplinary teams including vascular surgeons, interventional cardiologists, radiologists, and podiatrists among others provide an opportunity for shared decision-making that improves limb salvage rates and the overall care of patients with CLTI. ${ }^{3}$ Not all patients are suitable for revascularization, and major amputation remains an important treatment option in the management of CLTI. Patients may present with severe arterial disease, infections, or tissue loss beyond salvage that will require major amputation. Although often viewed as a failure of treatment, major amputations provide definitive therapy for unsalvageable disease. The use of the grading systems such as the Society for Vascular Surgery (SVS) Wound and Ischemia, Foot Infection (WIfI) classification system help to identify those at high risk for major amputation. ${ }^{4}$ In this article, we review the role of amputations in the care of patients with CLTI. stage of peripheral artery disease and is associated with high

\section{Epidemiology of Lower Extremity Amputations}

Major amputations are a common procedure with approximately 60,000 major amputations performed yearly in the United States. ${ }^{5-7}$ However, major amputations have been on the decline, with one study in the elderly population showing rates of major amputation, decreasing from 7,528 per 100,000 patients to 5,790 per 100,000 patients from 2000 to $2008 .{ }^{8}$ Similar trends have also been observed in countries such as Spain, Germany, Turkey, and the United Kingdom. ${ }^{9-12}$ However, there is significant variability in the incidence of major amputations globally, highlighting the importance of standardized methods in reporting to continue to monitor major amputations worldwide. ${ }^{13}$

There is significant variation in the rates of major amputation by ethnicity, socioeconomic factors, and geography. Navajo men have been observed to have particularly high rates of major amputation, attributed primarily to high rates of diabetes. ${ }^{14}$ African Americans also have higher rates of major amputation even after adjustment for comorbid 10.1055/s-0040-1710075. ISSN 1061-1711. 
conditions including diabetes. ${ }^{15,16}$ Global studies have also demonstrated significant variation in rates of major amputation, highlighting socioeconomic disparities and limited access to vascular specialists and health care. ${ }^{14,17,18}$ In Australia, aboriginal patients and those in rural areas were more likely to present with severe diabetic ulcers and undergo major amputation. ${ }^{19,20}$

Diabetes is the most significant risk factor for major amputation with an eightfold increase risk compared with the general population..$^{21-23}$ The lifetime risk of foot infections among diabetic patients is $25 \%$ and is the most important cause of major amputation in this group of patients. ${ }^{24,25}$ However, aggressive glucose control and medical optimization have been shown to lower this risk. ${ }^{26}$ Other important risk factors for major amputation in the setting of CLTI include end-stage renal disease (ESRD), peripheral neuropathy, and smoking. ${ }^{27-29}$

Endovascular procedures have extended the treatment of CLTI to many high-risk patients who were previously not candidates for open revascularization, and have been associated with decreased rates of major amputation. ${ }^{30}$ Improvements in medical therapy including antiplatelet therapy and statins in addition to better management of comorbid medical conditions have improved limb salvage rates and mortality. ${ }^{31,32}$ However, patients with CLTI still face low rates of overall survival at an average of 3.5 years, which is lower than other serious conditions including heart failure and many cancers. ${ }^{33-35}$

\section{The Role for Amputation}

Nearly all patients should be considered for revascularization before amputation. However, it remains an important tool for those with severe forms of CLTI with unreconstructible disease. This was recognized in the recently published Global Vascular Guidelines, which provided recommendations regarding the use of amputations in the management of CLTI. ${ }^{1}$ Minor amputations are those that involve the toes or portion of the foot, while major amputations imply more proximal limb loss (e.g., below or above knee amputation [BKA or AKA]). Minor amputations maintain the ability of the patient to bear their weight and seldom require a prosthetic unlike a major amputation. The primary goals of major amputation in the setting of CLTI are the relief of ischemic pain, removal of all diseased or necrotic tissue, and preservation of ambulation if possible. Additionally, major amputations should aim to limit reinterventions and provide an opportunity for rehabilitation or palliation as appropriate.

\section{Indications for Minor Foot Amputation}

Minor amputations including toe and forefoot amputations may be necessary for limb salvage and avoidance of major amputation. The indications for minor amputation include infection, osteomyelitis, gangrene, and neurotrophic feet ( - Table 1 ). As long as these processes do not extend beyond the forefoot preventing future ambulation, a minor foot amputation can avoid a major leg amputation and help maintain ambulation, functional status, and quality of life. Importantly, perfusion should be assessed to optimize healing following a minor amputation and prevent conversion to a major ampu-
Table 1 Indications for minor foot amputation

\begin{tabular}{|l|}
\hline - Infection with adequate perfusion. \\
\hline - Toe gangrene with small vessel arterial disease. \\
\hline - Neurotrophic foot with adequate perfusion. \\
\hline - Osteomyelitis or gangrene with adequate perfusion. \\
\hline
\end{tabular}

tation. When peripheral artery disease is present, revascularization is often required to establish in-line flow distally. For example, transmetatarsal amputations have shown high rates of success when coupled with revascularization procedures. $^{36,37}$ Sheahan et al demonstrated a limb salvage rate of $78 \%$ at 5 years for patients who underwent transmetatarsal amputation and revascularization. ${ }^{36}$

\section{Indications for Major Leg Amputation}

The indications for primary amputation in the setting of CLTI are unreconstructible arterial disease, destruction of the major weight-bearing portions of the foot, a nonfunctional lower extremity, severe comorbid conditions or limited life expectancy, and avoidance of a prolonged recovery with multiple high-risk surgical procedures (-Table 2). Of these indications, the most common reasons for major amputation include prior failed revascularization, extensive pedal gangrene, and unreconstructible arterial anatomy. ${ }^{38}$

Up to $20 \%$ of the patients with CLTI are found to have unreconstructible peripheral artery disease usually due to severe outflow disease with occluded tibial and pedal vessels. ${ }^{39,40}$ Unfortunately, this degree of disease is often not amenable to standard surgical or endovascular revascularization, and will often require major amputation. An attempt at revascularization may be attempted although outcomes of both open and endovascular revascularization are significantly worse with poor pedal and tibial outflow. ${ }^{41-44}$ Importantly, a proper vascular evaluation with imaging such as angiography or computed tomography angiography is necessary to properly assess all possible treatment options prior to deciding on major amputation for these reasons.

Major amputation also has a role in those with a nonfunctional lower extremity. This may occur in those with paralysis secondary to nerve damage or a stroke, and may be complicated by contractures, which can further limit mobility. Revascularization of a nonfunctional limb has limited utility, and an amputation may provide an opportunity for improved mobility.

Table 2 Indications for major leg amputation

\begin{tabular}{|l|}
\hline - Unreconstructible arterial disease. \\
\hline - Destruction of the major weight bearing areas of the foot. \\
\hline - Nonfunctional lower extremity. \\
\hline - Severe comorbid conditions or limited life expectancy. \\
\hline - Prolonged course requiring multiple procedures. \\
\hline
\end{tabular}


Destruction of major areas of the foot most often occurs in patients with severe foot tissue loss or foot infections. Patients with severe foot infections precluding a transmetatarsal amputation will often require major amputation. This is of particular importance in patients with diabetes and associated peripheral neuropathy given the high incidence of this complication. ${ }^{24,25}$ Similarly, patients with osteomyelitis or deep infections or abscesses involving an extensive portion of the foot or calcaneus should also be considered for major amputation. Severe tissue loss involving the foot preventing a transmetatarsal amputation, or extensive tissue loss at the heel should be considered for a major amputation. This includes severe wounds, ulcers, and gangrene extending to the forefoot or midfoot, or involving the heel with possible calcaneal involvement. In some cases, a complex reconstruction with skin flaps following debridement may be possible to avoid amputation.

Patients who have severe CLTI with multiple significant comorbid conditions may benefit from primary amputation. This includes nonambulatory patients or those with dementia due to poor outcomes and minimal improvement in quality of life following revascularization. Oresanya et al used Medicare claims to identify nonambulatory nursing home residents who underwent revascularization for CLTI, and demonstrated little benefits to revascularization in this population with minimal gained function and high rates of mortality over $50 \%$ at 1 year. $^{45}$

Similarly, primary amputation has the potential to avoid prolonged reinterventions and wound care regimens. This strategy applies primarily to elderly patients with multiple significant comorbidities, in which repeated high-risk surgical procedures with a low likelihood of success may place them at a high risk for complications. ${ }^{1,46}$ Revascularization in this group of patients often includes an extended hospital course or multiple readmissions, placing patients at increased risk for additional complications and a low quality of life. ${ }^{47,48}$ Primary amputation can avoid the prolonged immobility and deconditioning associated with a prolonged recovery, and may allow a faster return to independence or baseline functioning.

\section{Patient Selection for Major Amputation in CLTI}

A major amputation is an important treatment option in the care of patients with CLTI. A thoughtful and reasoned approach is important to making the decision between revascularization and amputation for those at high risk. The WIfI classification system has been shown to accurately predict the risk of limb loss better than prior grading systems, and is a useful tool to aid in the decision-making process. Robinson et al reviewed 257 patients with CLTI and found that increasing WIfl stage was associated with decreased limb salvage. ${ }^{49}$ At 1 year, patients with WIfl stage 4 disease had a $22 \%$ rate of major limb loss.

A thorough vascular evaluation including appropriate imaging is essential to proper decision-making. However, multiple studies have documented low rates of vascular evaluations prior to major amputation. ${ }^{33,50,51}$ Goodney et al used Medicare claims to show that $54 \%$ of the patients with CLTI did not have revascularization within a year of undergoing major amputation. $^{51}$

Identifying which patient should undergo major amputation rather than revascularization can be difficult, as many patients with severe CLTI have significant comorbidities. ${ }^{52}$ Suckow et al demonstrated that patients with multiple comorbidities and limited functional status at the time of surgery had higher rates of amputation following lower extremity bypass. ${ }^{47}$ Long-term follow-up of patients in the Project or Ex-Vivo vein graft Engineering via Transfection III (PREVENT III) trial found that patients deemed high risk due to multiple comorbidities including ESRD, tissue loss, age greater than 75, anemia, and coronary artery disease were more likely to end up with a major amputation, with rates exceeding 55\%. ${ }^{48}$ Additionally, a study using the Vascular Study Group of New England (VSGNE) registry found that factors including age, ESRD, diabetes, CLTI, spliced conduit, pedal target, and nursing home status were associated with increased risk of failure with revascularization. ${ }^{53}$ Studies comparing primary amputation versus amputation following revascularization among the elderly are mixed, with some finding higher rates of mortality following failed bypass. $^{54,55}$

The decision regarding revascularization versus amputation is a difficult and personal choice. This should involve a thoughtful discussion with the patient regarding appropriate expectations and outcomes. A survey of patients who underwent lower extremity amputation found that physician-controlled factors including timing, shared decision-making, and postamputation support had an important role in the decision-making process and quality of life. ${ }^{56}$ Interestingly, a study of amputees noted that several patients expressed a desire for amputation earlier in their clinical course. ${ }^{57} \mathrm{~A}$ high-risk revascularization procedure and wound care regimen with a prolonged course may not align with a patient's overall goals. This emphasizes the importance of shared decision-making and providing patients with the full range of surgical options and potential treatment courses during each step of their treatment.

\section{The Role of Multidisciplinary Teams in the Care of CLTI}

A multidisciplinary team approach to the care of patients with CLTI is supported by the SVS and improves outcomes. ${ }^{3}$ Specific members of the multidisciplinary team may vary by practice, but typically consist of at least a vascular surgeon and podiatrist. The goals of such a practice include podiatric and wound care, as well as vascular assessments and revascularization if necessary. ${ }^{3}$ This is of particular importance for diabetic patients who are at increased risk of limb loss. The inclusion of podiatrists has been shown to significantly reduce rates of major amputation. Integration of podiatrists into a health system in Michigan led to an increase in the diagnosis of diabetic foot ulcers and shifted a significant portion of care to the outpatient setting. ${ }^{58}$ The rate of major amputations decreased by $50 \%$, while preventative procedures such as debridement significantly increased. Similarly, the inclusion 
of podiatrists in the care of patients with diabetic ulcers in China led to a nearly ninefold reduction in major amputations among patients with severe diabetic ulcers. ${ }^{59}$

Multidisciplinary teams with podiatrists offer additional resources and care for the diabetic foot, and seek to prevent the development of uncontrolled infections and ultimately major amputation. The implementation of multidisciplinary teams has been shown to increase overall procedural volume as well as improve limb salvage rates. ${ }^{60-62}$ Our group has investigated the impact of a multidisciplinary team on limb salvage rates in patients with CLTI. ${ }^{60}$ The use of a multidisciplinary team led to significant increases in lower extremity revascularizations and minor amputations, and was associated with a significantly lower rate of major amputations. Similarly, Flores et al demonstrated that establishment of a multidisciplinary wound care center increased the volume of lower extremity revascularizations and improved limb salvage rates. ${ }^{61}$ An additional benefit observed in multiple studies was an increase in referrals and patient volume. ${ }^{3,60,61}$ The use of a multidisciplinary, team-based approach to CLTI increases preventative care and revascularization as opposed to reactive and urgent care, and leads to improved overall outcomes. ${ }^{63}$

Studies across multiple countries have also shown that the implementation of a multidisciplinary team reduced major amputations leading to significant cost savings. ${ }^{64-66}$ Using Markov models, diabetic patients treated by multidisciplinary teams with preventative measures lead to savings of $\$ 2,900$ to $\$ 4,442$ per patient costs. ${ }^{67}$

\section{The Impact and Outcomes of Major Amputation}

Long-term outcomes following major amputation remain poor, with relatively high rates of perioperative and longterm mortality. ${ }^{54,68}$ Mustapha et al demonstrated that patients with CLTI treated with primary amputation had significantly lower rates of survival and a higher risk of subsequent amputation over 4 years compared with revascularization. ${ }^{69}$ Even after propensity matching, those who underwent primary major amputation had a mean survival of 1.3 years compared with 2.7 and 2.9 years with endovascular and open revascularization, respectively. Jones et al demonstrated similar results among elderly patients, with a $70.9 \%$ mortality rate at 3 years. ${ }^{8}$ Additionally, proximal amputations, such as AKA, were associated with an even higher risk of mortality.

In addition to the high mortality rates, patients with major amputations will often require revisions and even conversion to a more proximal amputation. Aulivola et al demonstrated a reintervention rate of $18.4 \%$ for BKA and $4.7 \%$ for AKA. ${ }^{70}$ A separate study found that $25 \%$ of BKAs ultimately required conversion to an AKA. ${ }^{71}$

Functional outcomes following major amputation are largely dependent on preoperative comorbidities and functional status. Younger, ambulatory patients with fewer comorbidities can generally be expected to have functional outcomes similar to those with successful revascularization. ${ }^{72}$ Among those with healed stumps, up to $80 \%$ of the patients with a BKA can achieve ambulation, and up to $50 \%$ with an AKA may ambulate. ${ }^{73}$
However, many patients with CLTI have multiple comorbidities and experience a decline in functional status following major amputation. Taylor et al defined a successful outcome following BKA as wound healing without the need for revision, maintenance of ambulation for at least a year, and survival for at least 6 months postoperatively. The presence of coronary artery disease, cerebrovascular disease, and impaired preoperative ambulatory status decreased the odds of a successful outcome from 67.5 to $10.4 \%{ }^{74}$ A study of nursing home patients who underwent major amputation found that the majority of the patients did not return to their preoperative functional status within 6 months. ${ }^{75}$ Additionally, higher amputation level, ESRD, and dementia were associated with worse outcomes.

Patients who have a major amputation undergo significant life changes due to the loss of a limb. Quality of life following an amputation has been shown to be largely dependent on the ability to ambulate or return to previous functional status. ${ }^{76-79}$ These findings stress the importance of postamputation care and rehabilitation to regain mobility and maintain independence. In addition to quality of life, many studies have found increased rates of depression following amputation. ${ }^{68,80,81}$ Depression should be identified and treated promptly as it can slow the rehabilitation process and has been associated with further amputation. ${ }^{80}$

Raviola et al first demonstrated the increased cost of primary amputation compared with bypass surgery in $1988 .^{82}$ Since then, multiple studies have supported this finding, even with the use of endovascular interventions. ${ }^{83-85}$ Mustapha et al using Medicare claims to demonstrate increased costs associated with primary amputation compared with surgical or endovascular revascularization. ${ }^{33}$ After adjusting for follow-up duration, cost per patient year was $\$ 49,200$ for surgical revascularization, $\$ 49,700$ for endovascular revascularization, and $\$ 55,700$ for major amputation.

\section{Conclusion}

Amputation remains an important tool in the management of CLTI. Despite improvements in care and treatment, many patients still progress to severe forms of CLTI necessitating a major amputation. However, mortality following major amputation remains high, reflecting the poor health status of this population, and highlights multiple potential areas for improvement in limb salvage.

\section{Conflict of Interest}

C.M. is a consultant for Bard, Cook, Cardinal Health, Boston Scientific, and Medtronic. B.E.S. is a consultant for Hypermed.

\section{References}

1 Conte MS, Bradbury AW, Kolh P, et al; GVG Writing Group. Global vascular guidelines on the management of chronic limb-threatening ischemia. J Vasc Surg 2019;69(6S):3S-125S, e40

2 Almasri J, Adusumalli J, Asi N, et al. A systematic review and metaanalysis of revascularization outcomes of infrainguinal chronic limb-threatening ischemia. Eur J Vasc Endovasc Surg 2019;58 (1S):S110-S119 
3 Sumpio BE, Armstrong DG, Lavery LA, Andros G; SVS/APMA writing group. The role of interdisciplinary team approach in the management of the diabetic foot: a joint statement from the Society for Vascular Surgery and the American Podiatric Medical Association. J Vasc Surg 2010;51(06):1504-1506

4 Mills JL Sr, Conte MS, Armstrong DG, et al; Society for Vascular Surgery Lower Extremity Guidelines Committee. The Society for Vascular Surgery Lower Extremity Threatened Limb Classification System: risk stratification based on wound, ischemia, and foot infection (WIfI). J Vasc Surg 2014;59(01):220-234.e1-2

5 Harris CM, Albaeni A, Thorpe RJ, Norris KC, Abougergi MS. Racial factors and inpatient outcomes among patients with diabetes hospitalized with foot ulcers and foot infections, 2003-2014. PLoS One 2019;14(05):e0216832

6 Goldberg JB, Goodney PP, Cronenwett JL, Baker F. The effect of risk and race on lower extremity amputations among Medicare diabetic patients. J Vasc Surg 2012;56(06):1663-1668

7 Rowe VL, Lee W, Weaver FA, Etzioni D. Patterns of treatment for peripheral arterial disease in the United States: 1996-2005. J Vasc Surg 2009;49(04):910-917

8 Jones WS, Patel MR, Dai D, et al. High mortality risks after major lower extremity amputation in Medicare patients with peripheral artery disease. Am Heart J 2013;165(05):809-815, 815.e1

9 Rodríguez Pérez MDC, Chines C, Pedrero García AJ, et al. Major amputations in type 2 diabetes between 2001 and 2015 in Spain: regional differences. BMC Public Health 2020;20(01):54

10 Claessen H, Narres M, Haastert B, et al. Lower-extremity amputations in people with and without diabetes in Germany, 20082012-an analysis of more than 30 million inhabitants. Clin Epidemiol 2018;10:475-488

11 Krishnan S, Nash F, Baker N, Fowler D, Rayman G. Reduction in diabetic amputations over 11 years in a defined U.K. population: benefits of multidisciplinary team work and continuous prospective audit. Diabetes Care 2008;31(01):99-101

12 Karakoc A, Ersoy RU, Arslan M, Toruner FB, Yetkin I. Change in amputation rate in a Turkish diabetic foot population. J Diabetes Complications 2004;18(03):169-172

13 Moxey PW, Gogalniceanu P, Hinchliffe RJ, et al. Lower extremity amputations-a review of global variability in incidence. Diabet Med 2011;28(10):1144-1153

14 Unwin N. Epidemiology of lower extremity amputation in centres in Europe, North America and East Asia. Br J Surg 2000;87(03): 328-337

15 Mustapha JA, Fisher BT Sr, Rizzo JA, et al. Explaining racial disparities in amputation rates for the treatment of peripheral artery disease (PAD) using decomposition methods. J Racial Ethn Health Disparities 2017;4(05):784-795

16 Lefebvre KM, Lavery LA. Disparities in amputations in minorities. Clin Orthop Relat Res 2011;469(07):1941-1950

17 Feinglass J, Rucker-Whitaker C, Lindquist L, McCarthy WJ, Pearce WH. Racial differences in primary and repeat lower extremity amputation: results from a multihospital study. J Vasc Surg 2005; 41(05):823-829

18 Arya S, Binney Z, Khakharia A, et al. Race and socioeconomic status independently affect risk of major amputation in peripheral artery disease. J Am Heart Assoc 2018;7(02):e007425

19 Perrin BM, Allen P, Gardner MJ, et al. The foot-health of people with diabetes in regional and rural Australia: baseline results from an observational cohort study. J Foot Ankle Res 2019;12:56

20 West M, Chuter V, Munteanu S, Hawke F. Defining the gap: a systematic review of the difference in rates of diabetes-related foot complications in Aboriginal and Torres Strait Islander Australians and non-Indigenous Australians. J Foot Ankle Res 2017;10:48

21 Narres M, Kvitkina $\mathrm{T}$, Claessen $\mathrm{H}$, et al. Incidence of lower extremity amputations in the diabetic compared with the nondiabetic population: a systematic review. PLoS One 2017;12(08): e0182081
22 Ólafsdóttir AF, Svensson A-M, Pivodic A, et al. Excess risk of lower extremity amputations in people with type 1 diabetes compared with the general population: amputations and type 1 diabetes. BMJ Open Diabetes Res Care 2019;7(01):e000602

23 Holman N, Young RJ, Jeffcoate WJ. Variation in the recorded incidence of amputation of the lower limb in England. Diabetologia 2012;55(07):1919-1925

24 Uçkay I, Aragón-Sánchez J, Lew D, Lipsky BA. Diabetic foot infections: what have we learned in the last 30 years? Int J Infect Dis 2015;40:81-91

25 Singh N, Armstrong DG, Lipsky BA. Preventing foot ulcers in patients with diabetes. JAMA 2005;293(02):217-228

26 Suckow BD, Newhall KA, Bekelis K, et al. Hemoglobin A1c testing and amputation rates in Black, Hispanic, and White medicare patients. Ann Vasc Surg 2016;36:208-217

27 Kaminski MR, Raspovic A, McMahon LP, et al. Risk factors for foot ulceration and lower extremity amputation in adults with endstage renal disease on dialysis: a systematic review and metaanalysis. Nephrol Dial Transplant 2015;30(10):1747-1766

28 Gilhotra RA, Rodrigues BT, Vangaveti VN, Malabu UH. Prevalence and risk factors of lower limb amputation in patients with endstage renal failure on dialysis: a systematic review. Int J Nephrol 2016;2016:4870749

29 Baubeta Fridh E, Andersson M, Thuresson M, et al. Editor's Choice -impact of comorbidity, medication, and gender on amputation rate following revascularisation for chronic limb threatening ischaemia. Eur J Vasc Endovasc Surg 2018;56(05):681-688

30 Egorova NN, Guillerme S, Gelijns A, et al. An analysis of the outcomes of a decade of experience with lower extremity revascularization including limb salvage, lengths of stay, and safety. J Vasc Surg 2010;51(04):878-885, 885.e1

31 Chung J, Modrall JG, Ahn C, Lavery LA, Valentine RJ. Multidisciplinary care improves amputation-free survival in patients with chronic critical limb ischemia. J Vasc Surg 2015;61(01):162-169

32 Benoit E, O'Donnell TF Jr, Kitsios GD, Iafrati MD. Improved amputation-free survival in unreconstructable critical limb ischemia and its implications for clinical trial design and quality measurement. J Vasc Surg 2012;55(03):781-789

33 Mustapha JA, Katzen BT, Neville RF, et al. Determinants of longterm outcomes and costs in the management of critical limb ischemia: a population-based cohort study. J Am Heart Assoc 2018;7(16):e009724

34 Mozaffarian D, Benjamin EJ, Go AS, et al; Writing Group Members; American Heart Association Statistics Committee; Stroke Statistics Subcommittee. Heart disease and stroke statistics-2016 update: a report from the American Heart Association. Circulation 2016;133(04):e38-e360

35 Teraa M, Conte MS, Moll FL, Verhaar MC. Critical limb ischemia: current trends and future directions. J Am Heart Assoc 2016;5 (02):e002938

36 Sheahan MG, Hamdan AD, Veraldi JR, et al. Lower extremity minor amputations: the roles of diabetes mellitus and timing of revascularization. J Vasc Surg 2005;42(03):476-480

37 La Fontaine J, Reyzelman A, Rothenberg G, Husain K, Harkless LB. The role of revascularization in transmetatarsal amputations. J Am Podiatr Med Assoc 2001;91(10):533-535

38 Abou-Zamzam AM Jr, Teruya TH, Killeen JD, Ballard JL. Major lower extremity amputation in an academic vascular center. Ann Vasc Surg 2003;17(01):86-90

39 Slovut DP, Sullivan TM. Critical limb ischemia: medical and surgical management. Vasc Med 2008;13(03):281-291

40 Baghdasaryan PA, Bae JH, Yu W, et al. "The renal foot" -angiographic pattern of patients with chronic limb threatening ischemia and end-stage renal disease. Cardiovasc Revasc Med 2020;21 (01):118-121

41 Desai TR, Meyerson SL, Skelly CL, et al. Patency and limb salvage after infrainguinal bypass with severely compromised ("blind") outflow. Arch Surg 2001;136(06):635-642 
42 Biancari F, Albäck A, Ihlberg L, Kantonen I, Luther M, Lepäntalo M. Angiographic runoff score as a predictor of outcome following femorocrural bypass surgery. Eur J Vasc Endovasc Surg 1999;17 (06):480-485

43 Higashimori A, Iida O, Yamauchi Y, et al; OLIVE Investigators. Outcomes of one straight-line flow with and without pedal arch in patients with critical limb ischemia. Catheter Cardiovasc Interv 2016;87(01):129-133

44 Kawarada O, Yasuda S, Huang J, et al. Contemporary infrapopliteal intervention for limb salvage and wound healing: harmonization of revascularization and wound management. Circ J 2014;78(07): 1540-1549

45 Oresanya L, Zhao S, Gan S, et al. Functional outcomes after lower extremity revascularization in nursing home residents: a national cohort study. JAMA Intern Med 2015;175(06):951-957

46 Bertges DJ, Neal D, Schanzer A, et al; Vascular Quality Initiative. The vascular quality initiative cardiac risk index for prediction of myocardial infarction after vascular surgery. J Vasc Surg 2016;64 (05):1411-1421.e4

47 Suckow BD, Goodney PP, Cambria RA, et al; Vascular Study Group of New England. Predicting functional status following amputation after lower extremity bypass. Ann Vasc Surg 2012;26(01): $67-78$

48 Schanzer A, Goodney PP, Li Y, et al; Vascular Study Group of Northern New England. Validation of the PIII CLI risk score for the prediction of amputation-free survival in patients undergoing infrainguinal autogenous vein bypass for critical limb ischemia. J Vasc Surg 2009;50(04):769-775, discussion 775

49 Robinson WP, Loretz L, Hanesian C, et al. Society for Vascular Surgery Wound, Ischemia, foot infection (WIfI) score correlates with the intensity of multimodal limb treatment and patientcentered outcomes in patients with threatened limbs managed in a limb preservation center. J Vasc Surg 2017;66(02):488-498.e2

50 Allie DE, Hebert CJ, Lirtzman MD, et al. Critical limb ischemia: a global epidemic. A critical analysis of current treatment unmasks the clinical and economic costs of CLI. EuroIntervention 2005;1 (01):75-84

51 Goodney PP, Travis LL, Nallamothu BK, et al. Variation in the use of lower extremity vascular procedures for critical limb ischemia. Circ Cardiovasc Qual Outcomes 2012;5(01):94-102

52 Cruz CP, Eidt JF, Capps C, Kirtley L, Moursi MM. Major lower extremity amputations at a Veterans Affairs hospital. Am J Surg 2003;186(05):449-454

53 Goodney PP, Nolan BW, Schanzer A, et al; Vascular Study Group of Northern New England. Factors associated with amputation or graft occlusion one year after lower extremity bypass in northern New England. Ann Vasc Surg 2010;24(01):57-68

54 Klaphake S, de Leur K, Mulder PG, et al. Mortality after major amputation in elderly patients with critical limb ischemia. Clin Interv Aging 2017;12:1985-1992

55 Faglia E, Clerici G, Clerissi J, et al. Long-term prognosis of diabetic patients with critical limb ischemia: a population-based cohort study. Diabetes Care 2009;32(05):822-827

56 Suckow BD, Goodney PP, Nolan BW, et al. Domains that determine quality of life in vascular amputees. Ann Vasc Surg 2015;29(04): 722-730

57 Columbo JA, Davies L, Kang R, et al. Patient experience of recovery after major leg amputation for arterial disease. Vasc Endovascular Surg 2018;52(04):262-268

58 Schmidt BM, Holmes CM, Ye W, Pop-Busui R. A tale of two eras: mining big data from electronic health records to determine limb salvage rates with podiatry. Curr Diabetes Rev 2019;15(06): 497-502

59 Wang C, Mai L, Yang C, et al. Reducing major lower extremity amputations after the introduction of a multidisciplinary team in patient with diabetes foot ulcer. BMC Endocr Disord 2016;16(01):38

60 Sumpio BE, Aruny J, Blume PA. The multidisciplinary approach to limb salvage. Acta Chir Belg 2004;104(06):647-653
61 Flores AM, Mell MW, Dalman RL, Chandra V. Benefit of multidisciplinary wound care center on the volume and outcomes of a vascular surgery practice. J Vasc Surg 2019;70(05):1612-1619

62 Chandra V, Glebova NO, Salvo NL, Wu T. Partnerships between podiatrists and vascular surgeons in building effective wound care centers. J Vasc Surg 2017;66(03):902-905

63 Armstrong DG, Bharara M, White M, et al. The impact and outcomes of establishing an integrated interdisciplinary surgical team to care for the diabetic foot. Diabetes Metab Res Rev 2012;28(06):514-518

64 Joret MO, Osman K, Dean A, Cao C, van der Werf B, Bhamidipaty V. Multidisciplinary clinics reduce treatment costs and improve patient outcomes in diabetic foot disease. J Vasc Surg 2019;70 (03):806-814

65 Ragnarson Tennvall G, Apelqvist J. Prevention of diabetes-related foot ulcers and amputations: a cost-utility analysis based on Markov model simulations. Diabetologia 2001;44(11): 2077-2087

66 Driver VR, Fabbi M, Lavery LA, Gibbons G. The costs of diabetic foot: the economic case for the limb salvage team. J Vasc Surg 2010;52(Suppl 3):17S-22S

67 Ollendorf DA, Kotsanos JG, Wishner WJ, et al. Potential economic benefits of lower-extremity amputation prevention strategies in diabetes. Diabetes Care 1998;21(08):1240-1245

68 Peters CM, de Vries J, Veen EJ, et al. Is amputation in the elderly patient with critical limb ischemia acceptable in the long term? Clin Interv Aging 2019;14:1177-1185

69 Mustapha JA, Katzen BT, Neville RF, et al. Determinants of longterm outcomes and costs in the management of critical limb ischemia: a population-based cohort study. J Am Heart Assoc 2018;7(16):e009724

70 Aulivola B, Hile CN, Hamdan AD, et al. Major lower extremity amputation: outcome of a modern series. Arch Surg 2004;139 (04):395-399, discussion 399

71 Columbo JA, Nolan BW, Stucke RS, et al. Below-knee amputation failure and poor functional outcomes are higher than predicted in contemporary practice. Vasc Endovascular Surg 2016;50(08): 554-558

72 Taylor SM, Kalbaugh CA, Blackhurst DW, et al. Preoperative clinical factors predict postoperative functional outcomes after major lower limb amputation: an analysis of 553 consecutive patients. J Vasc Surg 2005;42(02):227-235

73 Robinson K. Amputation in vascular disease. Ann R Coll Surg Engl 1980;62(02):87-91

74 Taylor SM, Kalbaugh CA, Cass AL, et al. "Successful outcome" after below-knee amputation: an objective definition and influence of clinical variables. Am Surg 2008;74(07):607-612, discussion 612-613

75 Vogel TR, Petroski GF, Kruse RL. Impact of amputation level and comorbidities on functional status of nursing home residents after lower extremity amputation. J Vasc Surg 2014;59(05): 1323-30.e1

76 Peters CML, de Vries J, Lodder P, et al. Quality of life and not health status improves after major amputation in the elderly critical limb ischaemia patient. Eur J Vasc Endovasc Surg 2019;57(04):547-553

77 Pell JP, Donnan PT, Fowkes FGR, Ruckley CV. Quality of life following lower limb amputation for peripheral arterial disease. Eur J Vasc Surg 1993;7(04):448-451

78 Steunenberg SL, Raats JW, Te Slaa A, de Vries J, van der Laan L. Quality of life in patients suffering from critical limb ischemia. Ann Vasc Surg 2016;36:310-319

79 Davie-Smith F, Coulter E, Kennon B, Wyke S, Paul L. Factors influencing quality of life following lower limb amputation for peripheral arterial occlusive disease: a systematic review of the literature. Prosthet Orthot Int 2017;41(06):537-547

80 Williams LH, Miller DR, Fincke G, et al. Depression and incident lower limb amputations in veterans with diabetes. J Diabetes Complications 2011;25(03):175-182 
81 Parkes CM. Psycho-social transitions: comparison between reactions to loss of a limb and loss of a spouse. Br J Psychiatry 1975; 127:204-210

82 Raviola CA, Nichter LS, Baker JD, Busuttil RW, Machleder HI, Moore WS. Cost of treating advanced leg ischemia. Bypass graft vs primary amputation. Arch Surg 1988;123(04):495-496

83 Barshes NR, Chambers JD, Cohen J, Belkin M; Model to Optimize Healthcare Value in Ischemic Extremities 1 (MOVIE) Study Collaborators. Cost-effectiveness in the contemporary management of critical limb ischemia with tissue loss. J Vasc Surg 2012;56(04): 1015-24.e1

84 Mahoney EM, Wang K, Keo HH, et al; Reduction of Atherothrombosis for Continued Health (REACH) Registry Investigators. Vascular hospitalization rates and costs in patients with peripheral artery disease in the United States. Circ Cardiovasc Qual Outcomes 2010;3(06):642-651

85 Barshes NR, Kougias P, Ozaki CK, et al. Cost-effectiveness of revascularization for limb preservation in patients with marginal functional status. Ann Vasc Surg 2014;28(01):10-17 